\title{
Measurement of atmospheric $\mathrm{O}_{3} \rightarrow \mathrm{O}\left({ }^{1} \mathrm{D}\right)$ photolysis frequencies using filterradiometry
}

\author{
B. Bohn, A. Kraus, M. Müller, and A. Hofzumahaus \\ Institut für Chemie und Dynamik der Geosphäre II: Troposphäre, Forschungszentrum Jülich, Jülich, Germany
}

Received 3 November 2003; revised 12 January 2004; accepted 19 January 2004; published 20 May 2004.

[1] In this work the instrumentation and characterization of a filterradiometer suitable for field measurements of $\mathrm{O}_{3} \rightarrow \mathrm{O}\left({ }^{1} \mathrm{D}\right)$ photolysis frequencies, $j\left(\mathrm{O}^{1} \mathrm{D}\right)$, is described. A nonlinear calibration function considering ozone column and solar zenith angle is derived as well as a procedure utilizing an irradiance standard as an absolute reference. The measurement concept is tested by a field comparison with a spectroradiometer. Based solely on laboratory characterizations and simulated solar actinic flux spectra, a systematic deviation of $4 \%$ is obtained with a standard deviation of 3\% at solar zenith angles below $70^{\circ}$. The standard deviation rises to $8 \%$ at solar zenith angles in the range $70^{\circ}-85^{\circ}$. The systematic difference is within the accuracy of the applied radiometric calibrations while the standard deviation is mainly caused by insufficient synchronization of the different measurement techniques under variable field conditions. In addition, the relative temperature dependence of $j\left(\mathrm{O}^{1} \mathrm{D}\right)$ as a function of solar zenith angle and ozone column is derived which is applicable to any ground-based $j\left(\mathrm{O}^{1} \mathrm{D}\right)$ measurement. INDEX TERMS: 0360 Atmospheric Composition and Structure: Transmission and scattering of radiation; 0365 Atmospheric Composition and Structure: Troposphere — composition and chemistry; 0394 Atmospheric Composition and Structure: Instruments and techniques; KEYWORDS: Radiometry, photolysis frequency, ozone

Citation: Bohn, B., A. Kraus, M. Müller, and A. Hofzumahaus (2004), Measurement of atmospheric $\mathrm{O}_{3} \rightarrow \mathrm{O}\left({ }^{1} \mathrm{D}\right)$ photolysis frequencies using filterradiometry, J. Geophys. Res., 109, D10S90, doi:10.1029/2003JD004319.

\section{Introduction}

[2] Tropospheric chemistry is driven by the production of reactive radicals from photolysis of trace gases (ozone, nitrogen dioxide etc.) mainly by solar UV radiation $(\lambda \approx$ $300-400 \mathrm{~nm}$ ). Moreover, for many trace gases photolysis is a significant loss process competing with degradation by chemical reactions. Thus for an understanding of atmospheric photochemistry, important photolysis processes must be taken into account quantitatively and suitable measurements techniques are required.

[3] Ozone photolysis in the troposphere forming electronically excited $\mathrm{O}\left({ }^{1} \mathrm{D}\right)$ atoms,

$$
\mathrm{O}_{3}+h \nu \rightarrow \mathrm{O}\left({ }^{1} \mathrm{D}\right)+\mathrm{O}_{2}(\mathrm{a}, \mathrm{X})
$$

is of particular importance because the reaction of $\mathrm{O}\left({ }^{1} \mathrm{D}\right)$ with water vapor leads to $\mathrm{OH}$ radicals which are key reactive intermediates in tropospheric chemistry:

$$
\mathrm{O}\left({ }^{1} \mathrm{D}\right)+\mathrm{H}_{2} \mathrm{O} \rightarrow 2 \mathrm{OH}
$$

The photolysis process (1) is quantified by a first-order rate coefficient $j\left(\mathrm{O}^{1} \mathrm{D}\right)$ usually referred to as photolysis frequency:

$$
j\left(\mathrm{O}^{1} \mathrm{D}\right)=\frac{1}{\left[\mathrm{O}_{3}\right]} \frac{\mathrm{d}\left[\mathrm{O}^{1} \mathrm{D}\right]}{\mathrm{d} t}
$$

Copyright 2004 by the American Geophysical Union. 0148-0227/04/2003JD004319
Under tropospheric conditions, this rate coefficient is highly variable at a given location due to diurnal and seasonal variations and is sometimes subject to momentary variations (clouds). Thus for a field-measurement of $j\left(\mathrm{O}^{1} \mathrm{D}\right)$ a wide dynamic range and sufficient timeresolution $(\approx 1 \mathrm{~min})$ are crucial.

[4] There are two absolute techniques to measure local photolysis frequencies: chemical actinometry (CA) [Bahe et al., 1979, 1980; Dickerson et al., 1982] and spectroradiometry (SR) [Müller et al., 1995; Kraus and Hofzumahaus, 1998; Hofzumahaus et al., 1999; Shetter and Müller, 1999]. Chemical actinometry is a direct method where the photo-fragments (or secondary products) are monitored in a suitable reactor (e.g., a quartz flow-tube). The reactor contains a known concentration of the precursor molecule and is exposed to sunlight. For example, in the case of $\mathrm{O}\left({ }^{1} \mathrm{D}\right)$ an $\mathrm{O}_{3} / \mathrm{N}_{2} \mathrm{O}$ mixture can be used where $\mathrm{O}\left({ }^{1} \mathrm{D}\right)$ reacts with $\mathrm{N}_{2} \mathrm{O}$ to form $\mathrm{N}_{2}$ which is then detected [Müller et al., 1995]. Thus chemical actinometry is a process-specific method. The major drawback of this technique is that a complex instrument including a gas-handling system is needed to monitor a single photolysis process. As a consequence, chemical actinometry has not been widely used for field measurements.

[5] Spectroradiometry is using a different approach. Spectra of the absolute solar actinic photon flux $F_{\lambda}$ are recorded in the UV-range and photolysis frequencies are calculated using literature data of the wavelength-dependent 
absorption cross section $\sigma$ of the precursor molecule and the quantum yield $\phi$ of the photofragments:

$$
j=\int \sigma \phi F_{\lambda}(\lambda) \mathrm{d} \lambda
$$

While equation (4) has naturally been used for some time to calculate $j$-values from simulated solar actinic flux spectra based on radiation transfer models, this approach is relatively new for measured spectra. The reason is that on an absolute scale, spectroradiometry was, until recently, confined to the measurement of spectral irradiance $E_{\lambda}$ rather than actinic flux $F_{\lambda}$. Although these two variables have identical units $\left(\mathrm{cm}^{-2} \mathrm{~s}^{-1} \mathrm{~nm}^{-1}\right)$ they refer to different physical quantities: irradiance is a spectral photon flux normalized to a flat plane of acceptance while actinic flux is referring to the projection area of a spherical plane of acceptance [Madronich, 1987]. Unfortunately, there is no universally valid conversion between these quantities except for idealized conditions. However, recent work shows that conversions are feasible under field conditions (e.g., McKenzie et al. [2002]; Webb et al. [2002]; Kylling et al. [2003]).

[6] The main advantage of spectroradiometry is that from an actinic flux spectrum $F_{\lambda}(\lambda)$ the photolysis frequency of any photolysis process can be calculated provided the molecular data $\sigma$ and $\phi$ are available. Recent comparisons of chemical actinometers and spectroradiometers show that for $j\left(\mathrm{O}^{1} \mathrm{D}\right)$ and $j\left(\mathrm{NO}_{2}\right)$ there is good agreement of the techniques indicating that both the molecular data and the actinic flux measurement are reliable [Kraus et al., 2000; Hofzumahaus et al., 2004; Shetter et al., 2003]. However, since scanning double-monochromators are used to record the spectra, the time-resolution is limited to about $1 \mathrm{~min}$. Non-scanning combinations of a single-monochromator and a diode array presently seem not well suited for the measurement of $j\left(\mathrm{O}^{1} \mathrm{D}\right)$ due to an insufficient suppression of stray-light, at least at high solar zenith angles [Eckstein et al., 2002; Edwards and Monks, 2003].

[7] Filterradiometry (FR) is a simplified radiometric technique where the integrated solar actinic flux is monitored in a confined spectral interval [Junkermann et al., 1989; Volz-Thomas et al., 1996]. The idea is that if the relative spectral sensitivity of the instrument matches that of the product $\sigma \phi$ in equation (4), the output signal is proportional to $j$. Accordingly, also a filterradiometer can only refer to a single photolysis process. The main advantage is that such a device is a relatively inexpensive, light weight instrument which can be operated automatically providing continuous data sets with high time-resolution.

[8] However, while operation of a filterradiometer is easy (recording a radiation-dependent analog signal) calibration is more costly and resource intensive because the instrument must be calibrated against an absolute method (SR, CA) which requires the availability of such a reference [Junkermann et al., 1989; Volz-Thomas et al., 1996]. Moreover, in the case of $j\left(\mathrm{O}^{1} \mathrm{D}\right)$ data processing is complex because even small deviations from an ideal matching of the spectral sensitivity and the product $\sigma \phi$ produce significant nonlinearities in the relationship between $j\left(\mathrm{O}^{1} \mathrm{D}\right)$ and the radiometer signal. Earlier studies using $j\left(\mathrm{O}^{1} \mathrm{D}\right)$-filterradiometry have dealt differently with this problem. On the basis of a comparison with a chemical actionometer Junkermann et al. [1989] have estimated the uncertainties to be below $10 \%$ at solar zenith angles $(\chi)$ below $50^{\circ}$ and about a factor of two at $\chi=70^{\circ}$. Consequently, a constant calibration factor was applied only in a limited range of solar zenith angles. Also Shetter et al. [1996] made a comparison with a chemical actinometer and report deviations of the same magnitude.

[9] Hofzumahaus et al. [1992], Müller [1994] and Brauers et al. [1998] found similar deviations and applied a correction procedure taking into account solar zenith angle and ozone column. A related problem arises with measurements of erythemally weighted irradiances using broadband UV-B radiometers and corresponding corrections were developed for this purpose (e.g., Lantz et al. [1998]). In this paper the $j\left(\mathrm{O}^{1} \mathrm{D}\right)$ correction procedure is described in more detail. We will show that an accurate knowledge of both the molecular parameters $\left(\sigma\left(\mathrm{O}_{3}\right)\right.$, $\left.\phi\left(\mathrm{O}^{1} \mathrm{D}\right)\right)$ and the spectral sensitivity of the filterradiometer can be utilized to derive a zenith angle and ozone column dependent correction function by considering typical changes in the shape of the solar spectrum. This is attained by using simulated solar actinic flux spectra from a radiation transfer model. The concept is tested experimentally by a field-measurement comparison with a spectroradiometer. Moreover, on the same basis we will derive and test a correction for the effect of ambient temperature on $j\left(\mathrm{O}^{1} \mathrm{D}\right)$. Finally, we will show that an absolute calibration of a filterradiometer is also possible by using an irradiance standard, i.e., no chemical actinometer or spectroradiometer are essentially needed for calibration. However, it should be noted that the zenith angle and ozone column dependent correction is necessary in any case, regardless of the reference actually used.

\section{Instrumentation and Characterizations \\ 2.1. Instrumental Set-Up}

[10] The set-up of a filterradiometer is illustrated in Figure 1. The inlet optic is designed for a nearly uniform angular response to solar radiation incident from one hemisphere. This is accomplished by a sandblasted quartzdome (outer $\varnothing 32 \mathrm{~mm}$ ) and a shadow ring $(\varnothing 140 \mathrm{~mm}$, limiting the field of view to one hemisphere). Transmitted light is directed by a quartz light guide to a collimator in front of an interference filter (300 nm, FWHM $10 \mathrm{~nm}$ ) and a head-on photomultiplier (Hamamatsu, R-759). Also integrated in the housing is a current amplifier producing a signal which is fed into an external current-to-voltage amplifier. The housing is water-tight and thermostated by a heating device keeping the temperature constant at $(35 \pm$ $1)^{\circ} \mathrm{C}$. A combined high-voltage/power supply is connected with the radiometer by $25 \mathrm{~m}$-cables. An amplified DC output voltage is finally produced which can be recorded by any data logging system. The whole set-up is available commercially (Meteorologie Consult, Glashütten, Germany) with selected filter-detector combinations and adjusted quartz dome. However, these instruments are only monitoring one hemisphere, i.e., to cover the full sphere, two filterradiometers are needed or a single instrument can be rotated periodically. At field sites with high ground albedo (e.g., snow) care should be taken that a crosstalk 


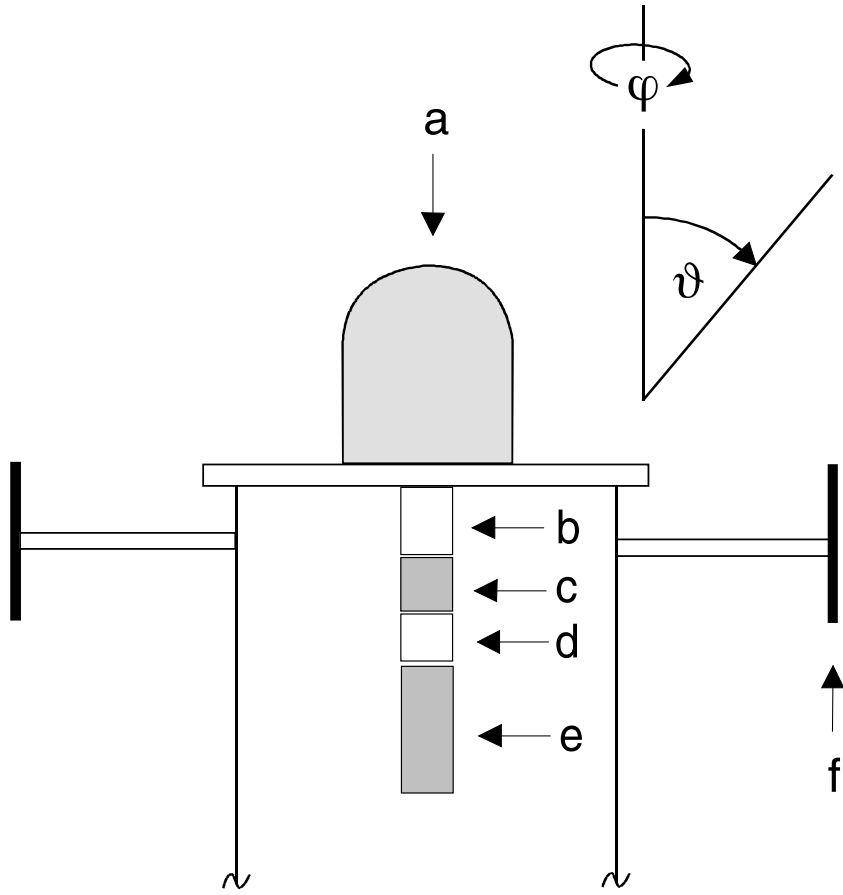

Figure 1. Instrumental set-up of a filterradiometer (vertical cut). a, sandblasted quartz dome (diffuser); b, quartz light-guide; c, collimator; $\mathrm{d}$, interference filter; e, photomultiplier; f, shadow ring.

to the other hemisphere is avoided for example by using a larger shadow ring.

[11] In the following the properties of a single, typical, radiometer will be described and the procedure of converting output signals to photolysis frequencies is explained for this particular instrument. Qualitatively, the situation is similar for any other filterradiometer.

\subsection{Output Signal of a Filterradiometer}

[12] The spectral signal output $\left(\mathrm{V} \mathrm{nm}^{-1}\right)$ of a filterradiometer is given by the following equation:

$$
U_{\lambda}=\int_{0}^{2 \pi} \int_{0}^{\pi / 2} D(\lambda, \vartheta) L_{\lambda}(\lambda, \vartheta, \varphi) \sin (\vartheta) \mathrm{d} \vartheta \mathrm{d} \varphi
$$

The integration limits cover the $2 \pi$ sr solid angle field of view of the device. $L_{\lambda}$ is the solar spectral photon radiance $\left(\mathrm{cm}^{-2} \mathrm{~s}^{-1} \mathrm{sr}^{-1} \mathrm{~nm}^{-1}\right) . D(\lambda, \vartheta)$ is the absolute, spectral and angular sensitivity of the device which, due to its rotational symmetry, is usually independent of the azimuth angle $\varphi$. The relative polar angle and wavelength dependencies of $D(\lambda, \vartheta)$ can be described by separate, dimensionless functions $D_{\text {rel }}$ and $Z_{\mathrm{p}}$ :

$$
D(\lambda, \vartheta)=D_{\text {abs }} D_{\text {rel }}(\lambda) Z_{\mathrm{p}}(\vartheta)
$$

If this is inserted into equation (5) the $\vartheta$-independent terms can be taken out of the integral:

$$
U_{\lambda}=D_{\text {abs }} D_{\text {rel }}(\lambda) \int_{0}^{2 \pi} \int_{0}^{\pi / 2} Z_{\mathrm{p}}(\vartheta) L_{\lambda}(\lambda, \vartheta, \varphi) \sin (\vartheta) \mathrm{d} \vartheta \mathrm{d} \varphi
$$

For atmospheric conditions the remaining integral can be expressed in terms of a product $Z_{\mathrm{H}} F_{\lambda}$ where $Z_{\mathrm{H}}$ is a dimensionless factor (dependent on the shape of $Z_{\mathrm{p}}$ [Hofzumahaus et al., 1999]) and $F_{\lambda}$ is the $2 \pi$ sr solar spectral actinic flux:

$$
U_{\lambda}=D_{\text {abs }} D_{\text {rel }}(\lambda) Z_{\mathrm{H}} F_{\lambda}(\lambda)
$$

The output voltage $U$ of the filterradiometer is finally obtained by integration:

$$
U=D_{\text {abs }} Z_{\mathrm{H}} \int D_{\text {rel }}(\lambda) F_{\lambda}(\lambda) \mathrm{d} \lambda
$$

This equation describes the relationship between the actinic flux spectrum and the output signal of the filterradiometer. The terms related with the instrumental properties are described in more detail in the following. The product $D_{\text {abs }} Z_{\mathrm{H}}$ can be obtained by laboratory characterizations (section 2.4 and 2.5) or by a field comparison with a spectroradiometer or chemical actinometer (section 3.4). In any case the relative sensitivity spectrum $D_{\text {rel }}$ is a crucial property of any filterradiometer which has to be determined in the laboratory.

\subsection{Sensitivity Spectrum: $D_{\text {rel }}$}

[13] A combination of a xenon arc lamp (R 300, IRCTechnologies) and a double-monochromator (Bentham, DTM 300) is utilized as a tunable light source for the spectral characterization of the filterradiometer in the laboratory. A calibrated silicon photodiode (Hamamatsu, S 1220-1010 BQ) is used as a reference detector with known spectral sensitivity $( \pm 2 \%$, PTB traceable). Lamp spectra with $1.0 \mathrm{~nm}$ FWHM are recorded with both the filterradiometer and the photodiode. The ratio of these spectra is multiplied by the sensitivity spectrum of the diode. Normalization to the maximum then leads to the relative sensitivity spectrum $D_{\text {rel }}(\lambda)$ of the filterradiometer. It should be noted that due to the strongly increasing solar actinic flux toward longer wavelengths $D_{\text {rel }}$ must be determined with high precision $\left( \pm 10^{-5}\right.$ or better $)$ in that range which is most important for the following considerations. It was therefore necessary to bypass the regular in-built amplification and to read out the PMT photocurrent directly with a current-to-voltage amplifier with sufficient dynamic range (Bentham, 228A).

[14] Figure 2 shows $D_{\text {rel }}$ of the filterradiometer under consideration. Also shown in Figure 2 is the wavelength dependence of the product $\sigma\left(\mathrm{O}_{3}\right) \phi\left(\mathrm{O}^{1} \mathrm{D}\right)$ at a temperature of 295 K [Malicet et al., 1995; Talukdar et al., 1998], which, on a relative basis, resembles that of $D_{\text {rel }}$ quite well, at least from the instrumental point of view and in the wavelength range relevant for tropospheric conditions $(\lambda \geq 300 \mathrm{~nm})$. However, the matching is not ideal as will be shown in section 3.1.

\subsection{Angular Response Function: $Z_{\mathrm{p}}, Z_{\mathrm{H}}$}

[15] As intimated above, the inlet optic is designed to receive radiation with a detection sensitivity as isotropic as possible [Hofzumahaus et al., 1999]. In contrast, a flat detector for the measurement of irradiances, is weighting the incident light by the cosine of the polar angle $\vartheta$. The relative angular response function $Z_{\mathrm{p}}$ of the filterradiometer as a function of $\vartheta$ is determined in the laboratory by a rotatable lamp with the rotation axis leading through the 


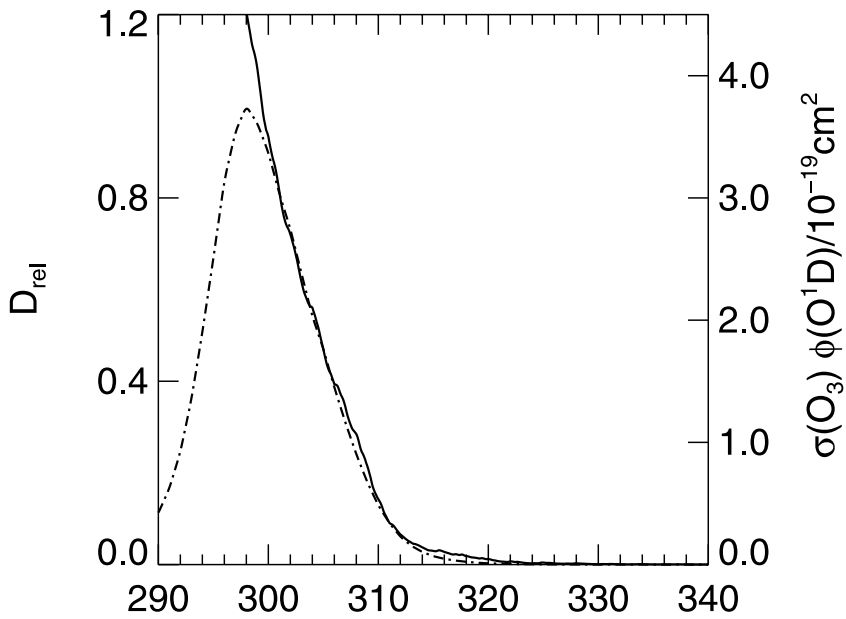

$\lambda / \mathrm{nm}$

Figure 2. Relative spectral sensitivity $D_{\text {rel }}$ of the $j\left(\mathrm{O}^{1} \mathrm{D}\right)$ filterradiometer (dashed line, left axis) and product $\sigma\left(\mathrm{O}_{3}\right)$ $\phi\left(\mathrm{O}^{1} \mathrm{D}\right)$ at a temperature of $295 \mathrm{~K}$ (full line, right axis) [Malicet et al., 1995; Talukdar et al., 1998]. The plot-ranges were chosen to demonstrate the good relative agreement in the relevant wavelength range above $300 \mathrm{~nm}$ (tropospheric conditions).

detector head. By carefully adjusting the relative position of the quartz dome and the shadow ring an almost constant response can be obtained as a function of the polar angle in the range $0 \leq \vartheta \leq \pi / 2$. The resulting angular response function $Z_{\mathrm{p}}(\vartheta)$ is normalized to the value obtained at $\vartheta=0$ (perpendicular incidence). A similar inlet optic is used with the spectroradiometer operated at Forschungszentrum Jülich and more details concerning the determination of the $Z_{\mathrm{p}}$ function are given elsewhere [Hofzumahaus et al., 1999]. Deviations from an ideal behavior of $Z_{\mathrm{p}}$, i.e., $Z_{\mathrm{p}}=1.0$ at $0 \leq$ $\vartheta \leq \pi / 2$, are considered quantitatively by the factor $Z_{\mathrm{H}}$ in equations (8) and (9). The factor $Z_{\mathrm{H}}$ is usually close to unity within $\pm 5-10 \%$ and only weakly dependent on solar zenith angle especially in the UV-B. More details concerning this factor are given by Hofzumahaus et al. [1999]. In the present case $Z_{\mathrm{H}}=0.92 \pm 0.02$ was derived for the filterradiometer under consideration with a negligible zenith angle dependence $(\leq 1 \%)$.

\subsection{Absolute Sensitivity Factor: $\boldsymbol{D}_{\text {abs }}$}

[16] An absolute radiometric calibration of the filterradiometer was made in the laboratory with a standard tungsten quartz-halogen lamp (Gigahertz Optik, FEL 1000, PTBtraceable) with known absolute irradiance spectrum $E_{\lambda}^{\text {st }}(\lambda)$ at a certain reference distance $(700 \mathrm{~mm})$. Actinic flux and irradiance are identical upon irradiation with a point light source at $\vartheta=0$ but with a spherical detector the correct distance between light source and detector is not as easily defined as with a flat detector. However, as was shown elsewhere [Hofzumahaus et al., 1999] a spherical detector also has a plane of reference which can be determined experimentally at $\vartheta=0$. It typically lies roughly in the middle between the top of the quartz dome and the front plate of the filterradiometer. With the irradiance standard mounted in the correct distance, an output voltage $U^{\text {st }}$ is measured from which the absolute sensitivity factor $D_{\text {abs }}$ is calculated according to the following equation:

$$
D_{\text {abs }}=\frac{U^{\text {st }}}{\int D_{\text {rel }}(\lambda) E_{\lambda}^{\text {st }}(\lambda) \mathrm{d} \lambda}
$$

The output voltage was $(116.4 \pm 0.5) \mathrm{mV}$ for the $1000 \mathrm{~W}$ standard mounted in a distance of $700 \mathrm{~mm}$ (under field conditions signal levels typically reach $1-5 \mathrm{~V}$ ). For this particular instrument $D_{\mathrm{abs}}=(6.65 \pm 0.40) \cdot 10^{-14} \mathrm{~V} \mathrm{~cm}^{2} \mathrm{~s}$ was obtained where the $6 \%$ error limit is estimated from the uncertainties of the irradiance standard (4\%) and the correct reference distance $(2 \%)$.

\section{Determination of Photolysis Frequencies}

\subsection{General Considerations}

[17] If equation 4 is divided by equation 9 a calibration factor $A$ is obtained which converts the filterradiometer signal to $j\left(\mathrm{O}^{1} \mathrm{D}\right)$ :

$$
\begin{aligned}
A & =\frac{j\left(\mathrm{O}^{1} \mathrm{D}\right)}{U} \\
& =\frac{1}{D_{\mathrm{abs}} Z_{\mathrm{H}}} \frac{\int \sigma \phi F_{\lambda}(\lambda) \mathrm{d} \lambda}{\int D_{\mathrm{rel}}(\lambda) F_{\lambda}(\lambda) \mathrm{d} \lambda}
\end{aligned}
$$

Here $\sigma=\sigma\left(\mathrm{O}_{3}\right)$ and $\phi=\phi\left(\mathrm{O}^{1} \mathrm{D}\right)$. As explained in the Introduction, the general idea of filterradiometry is to select a combination of filter and detector so that $D_{\text {rel }} \propto \sigma \phi$. If this were achieved, $A$ would be a simple factor and would not depend on the shape of the actinic flux spectrum $F_{\lambda}(\lambda)$. However, there are two problems with this approach.

[18] Firstly, an exact matching cannot be achieved technically as is shown in Figure 3a. That would pose no problem if the wavelength-dependence of $F_{\lambda}$ would always be the same except from a scaling factor. In this case also an imperfect matching of $\sigma \phi$ and $D_{\text {rel }}$ results in a constant factor $A$ (approximately fulfilled in the UV-A range, e.g., for a $j\left(\mathrm{NO}_{2}\right)$ filterradiometer). However, ozone photolysis takes place in the UV-B range limited by absorption by stratospheric ozone, i.e., the spectrum in this region is strongly dependent on solar zenith angle and ozone column $\left(t_{\mathrm{O}_{3}}\right)$ exemplified in Figure $3 b$. This affects $j\left(\mathrm{O}^{1} \mathrm{D}\right)$ and the output of the filterradiometer differently as is shown in Figures $3 \mathrm{c}$ and $3 \mathrm{~d}$. As an example Figures $3 \mathrm{e}$ and $3 \mathrm{f}$ summarize the resulting nonlinearities within a two-week field campaign.

[19] Secondly, the wavelength dependence of the product $\sigma \phi$ changes with temperature (T) making the proportionality factor dependent on ambient conditions. Again, in the case of $\mathrm{NO}_{2}$ photolysis this effect is minor and can be neglected in good approximation. However, in the case of ozone photolysis the quantum yield of $\mathrm{O}\left({ }^{1} \mathrm{D}\right)$ is strongly temperature dependent in the long-wavelength tail $(\lambda \geq 310 \mathrm{~nm})$ of the ozone absorption spectrum marking the energetic threshold range of spin-allowed $\mathrm{O}\left({ }^{1} \mathrm{D}\right)$ formation. This range is very important for tropospheric ozone photolysis.

[20] Thus the proportionality factor is generally considered a function of solar zenith angle, ozone column and ambient temperature:

$$
A=A\left(\chi, t_{\mathrm{O}_{3}}, T\right)
$$



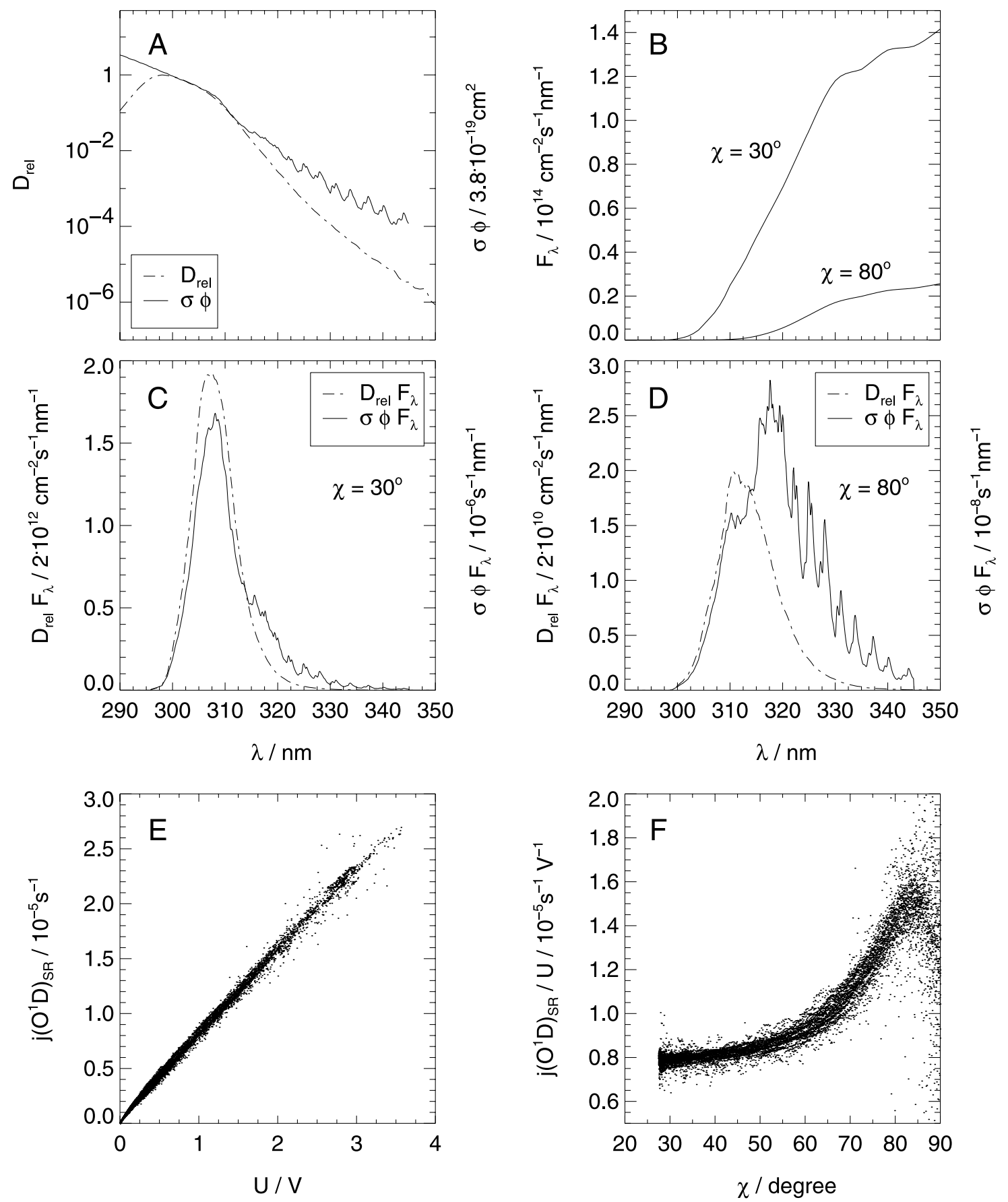

Figure 3. Demonstration of the effects caused by an imperfect matching of $D_{\text {rel }}$ and the product $\sigma\left(\mathrm{O}_{3}\right) \phi\left(\mathrm{O}^{1} \mathrm{D}\right)$. (a) Semi-logarithmic plot of the data of Figure 2 revealing small absolute, but significant relative differences at wavelengths above $315 \mathrm{~nm}$. (b) Simulated solar actinic flux spectra $F_{\lambda}$ at two distinct solar zenith angles $\chi=30^{\circ}$ and $\chi=80^{\circ}$ at an ozone column $t_{\mathrm{O}_{3}}=360 \mathrm{DU}$. (c, d) The products $D_{\text {rel }} F_{\lambda}$ and $\sigma \phi F_{\lambda}$ for the different zenith angles. $j\left(\mathrm{O}^{1} \mathrm{D}\right)$ corresponds to the integrals underneath the $\sigma \phi F_{\lambda}$ curves (equation (4)). The FR output signal $U$ is proportional to the integrals underneath the $D_{\text {rel }} F_{\lambda}$ curves (equation (9)). Obviously, the ratio $j\left(\mathrm{O}^{1} \mathrm{D}\right)_{\mathrm{SR}} / U$, i.e., the desired proportionality factor, is strongly $\chi$-dependent. Nevertheless, a correlation (e) of field campaign data of $j\left(\mathrm{O}^{1} \mathrm{D}\right)_{\mathrm{SR}}$ (measured with a spectroradiometer) and $U$ looks reasonable because both quantities decrease strongly with $\chi$. However, a plot (f) of the ratio $j\left(\mathrm{O}^{1} \mathrm{D}\right)_{\mathrm{SR}} / U$ as a function of $\chi$ reveals the expected strong dependence. More details concerning the field campaign data are given in section 4.1 . 
For practical reasons $A$ is separated into a fixed factor $A_{0}$ at selected reference conditions $\left(\chi^{\circ}, t_{\mathrm{O}_{3}}^{\circ}, T^{\circ}\right)$ and a dimensionless function $f$, describing the relative dependence on zenith angle, ozone column and ambient temperature:

$$
A=A_{0} f\left(\chi, t_{\mathrm{O}_{3}}, T\right)
$$

with

$$
A_{0}=A\left(\chi^{\circ}, t_{\mathrm{O}_{3}}^{\circ}, T^{\circ}\right)
$$

and

$$
f\left(\chi^{\circ}, t_{\mathrm{O}_{3}}^{\circ}, T^{\circ}\right)=1.0
$$

Moreover, because the temperature dependence of $f\left(\mathrm{x}, t_{\mathrm{O}_{3}}, T\right)$ has nothing to do with any instrumental property it can be described by a separate factor $b\left(\chi, t_{\mathrm{O}_{3}}, T\right)$ of general applicability corresponding to the relative temperature dependence of $j\left(\mathrm{O}^{1} \mathrm{D}\right)$ :

$$
b=\frac{j\left(\mathrm{O}^{1} \mathrm{D}\right)\left(\chi, t_{\mathrm{O}_{3}}, T\right)}{j\left(\mathrm{O}^{1} \mathrm{D}\right)\left(\chi, t_{\mathrm{O}_{3}}, T^{\circ}\right)}
$$

Thus $j\left(\mathrm{O}^{1} \mathrm{D}\right)$ is calculated from the measured voltage $U$ by applying three factors:

$$
j\left(\mathrm{O}^{1} \mathrm{D}\right)=A_{0} f\left(\chi, t_{\mathrm{O}_{3}}, T^{\circ}\right) b\left(\chi, t_{\mathrm{O}_{3}}, T\right) U
$$

Multiplication with $A_{0}$ provides a quick conversion into an approximate $j\left(\mathrm{O}^{1} \mathrm{D}\right)$ value where $A_{0}$ can be obtained from an intercomparison with a spectroradiometer (or chemical actinometer) or from a laboratory calibration with an irradiance standard (section 3.4). In a more thorough analysis of the data the factors $f\left(\mathrm{x}, t_{\mathrm{O}_{3}}, T^{\circ}\right)$ and $b\left(\mathrm{x}, t_{\mathrm{O}_{3}}, T\right)$ are then applied by taking into account actual solar zenith angles, ozone columns and ambient temperatures. The factors $f\left(\chi, t_{\mathrm{O}_{3}}, T^{\circ}\right)$ and $b\left(\chi, t_{\mathrm{O}_{3}}, T\right)$ are derived on the basis of simulated actinic flux spectra as described in the next sections.

\subsection{Calculation of $f\left(\chi, t_{\mathrm{O}_{3}}, T^{\circ}\right)$}

[21] The factor $f\left(\chi, t_{\mathrm{O}_{3}}, T^{\circ}\right)$ is defined by:

$$
f\left(\chi, t_{\mathrm{O}_{3}}, T^{\circ}\right)=\frac{A\left(\chi, t_{\mathrm{O}_{3}}, T^{\circ}\right)}{A_{0}}=\frac{Z_{H}\left(\chi^{\circ}\right)}{Z_{H}(\chi)} \frac{\int \sigma \phi F_{\lambda} \mathrm{d} \lambda}{\int \sigma \phi F_{\lambda}^{\circ} \mathrm{d} \lambda} \frac{\int D_{\mathrm{rel}} F_{\lambda}^{\circ} \mathrm{d} \lambda}{\int D_{\mathrm{rel}} F_{\lambda} \mathrm{d} \lambda}
$$

As mentioned above, the ratio $Z_{H}\left(\chi^{\circ}\right) / Z_{H}(\chi)$ is close to unity and will be neglected in the following. Taking $\chi^{\circ}=$ $30^{\circ}$ and $t_{\mathrm{O}_{3}}^{\circ}=350 \mathrm{DU}, f\left(\mathrm{x}, t_{\mathrm{O}_{3}}, T^{\circ}\right)$ has been calculated with the experimentally obtained spectral sensitivity $D_{\text {rel }}$ and 120 simulated solar actinic flux spectra from a radiation transfer model (E.-P. Röth, private communication, 1998). The spectra were calculated for 12 ozone columns in the range $t_{\mathrm{O}_{3}}=240-460 \mathrm{DU}$ and 10 solar zenith angles each in the range $\chi=0-87^{\circ}$ at ground level (clear sky conditions, albedo $=0.1)$. The model uses a pseudo-spherical radiative transfer algorithm with 11 beams and assumes a continental standard aerosol profile (WCP-112, WMO/TD-24, 1996) corresponding to aerosol optical depths of 0.47 and 0.44 at $300 \mathrm{~nm}$ and $330 \mathrm{~nm}$, respectively. More details concerning the applied model can be found in the IPMMI model intercomparison paper by Bais et al. [2003].

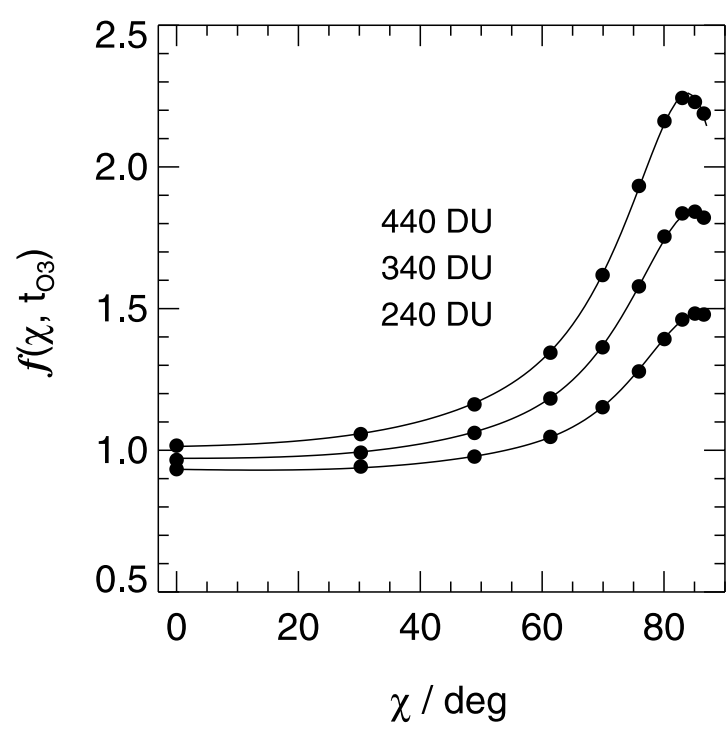

Figure 4. Factors $f\left(\chi, t_{\mathrm{O}_{3}}, T^{\circ}\right)$ according to equation (18) (solid circles) at a temperature of $295 \mathrm{~K}$. The data are normalized to reference conditions $t_{\mathrm{O}_{3}}=350 \mathrm{DU}$ and $\chi=$ $30^{\circ}$. The full lines show a parametrization of the data. The results of calculations for 3 out of 12 ozone columns in the range 240-460 DU are shown.

[22] For $\sigma\left(\mathrm{O}_{3}\right)$ and $\phi\left(\mathrm{O}^{1} \mathrm{D}\right)$ in equation (18) data by Malicet et al. [1995] and Talukdar et al. [1998] were used, respectively. A reference temperature of $T^{\circ}=295 \mathrm{~K}$ was selected as this was the highest temperature employed by Malicet et al. [1995]. The reason for choosing this combination of molecular data is not self-evident. The studies by Malicet et al. [1995] and Talukdar et al. [1998] represent the most extensive temperature dependent work on both molecular parameters while at room temperature the agreement with other recent studies is excellent. Thus as temperature dependent data are needed in the next section, the data by Malicet et al. [1995] and Talukdar et al. [1998] are used for consistency reasons.

[23] The integrals in equation 18 were numerically gained by summations at a wavelength resolution of $0.1 \mathrm{~nm}$. For this the original resolution of $\sigma\left(\mathrm{O}_{3}\right)$ [Malicet et al., 1995] was reduced by a factor of 10 by averaging while the resolution of $\phi\left(\mathrm{O}^{1} \mathrm{D}\right)$ [Talukdar et al., 1998] and $F_{\lambda}$ were artificially increased by interpolations by a factor of 10 and $10-50(\lambda \geq 315 \mathrm{~nm})$, respectively. Some of the resulting discrete values of $f\left(\chi, t_{\mathrm{O}_{3}}, T^{\circ}\right)$ are plotted in Figure 4 where a marked dependence on both zenith angle and ozone column is recognizable. A suitable parametrization was derived allowing a calculation for any combination of solar zenith angle and ozone column in the ranges considered.

\subsection{Calculation of $b\left(\chi, t_{\mathrm{O}_{3}}, T\right)$ - Temperature Dependence of $\boldsymbol{j}\left(\mathrm{O}^{1} \mathrm{D}\right)$}

[24] From equation (16) follows:

$$
b\left(\chi, t_{\mathrm{O}_{3}}, T\right)=\frac{\int \sigma(T) \phi(T) F_{\lambda} \mathrm{d} \lambda}{\int \sigma\left(T^{\circ}\right) \phi\left(T^{\circ}\right) F_{\lambda} \mathrm{d} \lambda}
$$




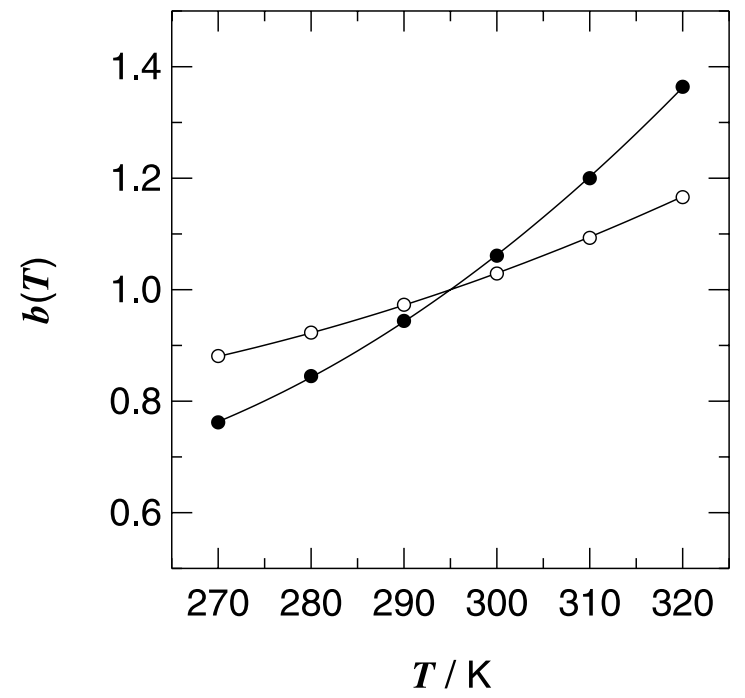

Figure 5. Relative temperature dependence $b\left(\mathrm{\chi}, t_{\mathrm{O}}, T\right)$ of $j\left(\mathrm{O}^{1} \mathrm{D}\right)$ at the lowest and highest ozone columns considered, combined with low and high zenith angles, respectively, marking the weakest and strongest dependence within the ranges covered. (open symbols) $t_{\mathrm{O}_{3}}=240 \mathrm{DU}, \chi=0^{\circ}$; (solid symbols) $t_{\mathrm{O}_{3}}=460 \mathrm{DU}, \chi^{3}=85^{\circ}$. Here 6 out of 51 calculated values are shown for each combination. The full lines show a parametrization as a function of solar zenith angle and ozone column.

The calculation was made according to equation 19 from the same set of simulated actinic flux spectra as used in the previous section in a temperature range $270-320 \mathrm{~K}$ with a step-size of $1 \mathrm{~K}$. Since absorption cross sections of ozone are not available in literature for temperatures above room temperature, the data by Malicet et al. [1995] (a total of five spectra at 218,228,243, 273 and $295 \mathrm{~K}$ ) were fitted by second-order polynomials for each wavelength position. This procedure has been recommended by Malicet et al. [1995] for interpolation and is used here also for extrapolation up to $T=320 \mathrm{~K}$. Because of the smooth change of absorption cross sections with temperature, this procedure appears to be justified. Talukdar et al. [1998] measured O $\left({ }^{1} \mathrm{D}\right)$ quantum yields at six temperatures in the range $209-320 \mathrm{~K}$. A parametrization given by Talukdar et al. [1998] is used to calculate the quantum yields in the temperature range considered here. Again the integrals in equation 19 were approximated by summations as in the previous section. In Figure $5, b\left(\chi, t_{\mathrm{O}_{3}}, T\right)$ is displayed as a function of temperature at the maximum and minimum values of ozone column and solar zenith angles covered by the simulated spectra. For all other zenith angles and ozone columns the relative temperature changes are within these extremes. As is evident from Figure 5, at high zenith angles and high ozone columns $j\left(\mathrm{O}^{1} \mathrm{D}\right)$ can vary by a factor of two in the range of temperatures considered here $(270-320 \mathrm{~K})$. A parametrization for $b\left(\chi, t_{\mathrm{O}_{3}}, T\right)$ has been derived which is shown in Figure 5 and given in the Appendix.

\subsection{Determination of $\boldsymbol{A}_{\mathbf{0}}$}

[25] There are two general methods to determine the factor $A_{0}$. The first method requires the availability of an absolute reference method, i.e., a spectroradiometer or a chemical actinometer recording data simultaneously with the filterradiometer. $A_{0}$ can then be calculated using equation 17 , by plotting the product $U f\left(\mathrm{\chi}, t_{\mathrm{O}_{3}}, T^{\circ}\right) b\left(\chi, t_{\mathrm{O}_{3}}, T\right)$ as a function of $j\left(\mathrm{O}^{1} \mathrm{D}\right)_{\text {Ref }}$ and performing a linear regression. In the case where a spectroradiometer is used as a reference the factor $b\left(\chi, t_{\mathrm{O}_{3}}, T\right)$ can be neglected in the determination of $A_{0}$ if $j\left(\mathrm{O}^{1} \mathrm{D}\right)_{\mathrm{SR}}$ is calculated for $T=T^{\circ}$. However, if a chemical actinometer is used as a reference, the temperature inside the actionometer must be considered (section 4.2). Both reference methods have been applied for calibration in previous work [Hofzumahaus et al., 1992; Brauers et al., 1998].

[26] In this work a different approach is tested by utilizing the laboratory calibration with an irradiance standard. From equations (10) and (17) the following expression is derived for $A_{0}$ :

$$
A_{0}=\frac{1}{D_{\mathrm{abs}} Z_{\mathrm{H}}\left(\chi^{\circ}\right)} \frac{\int \sigma \phi F_{\lambda}^{\circ} \mathrm{d} \lambda}{\int D_{\mathrm{rel}} F_{\lambda}^{\circ} \mathrm{d} \lambda}
$$
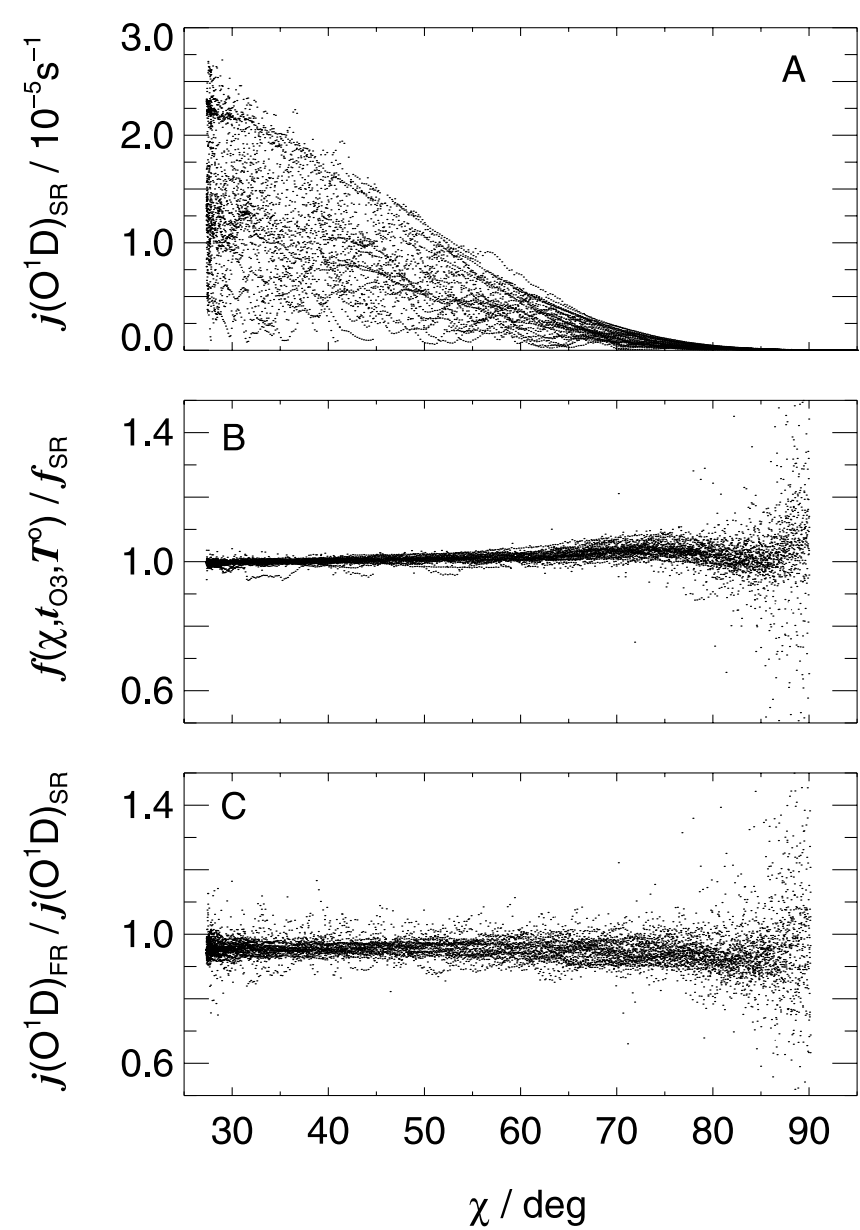

Figure 6. (a) Dependence of $j\left(\mathrm{O}^{1} \mathrm{D}\right)_{\mathrm{SR}}$ on solar zenith angle during the JCOM97 field campaign illustrating the strong variability of external conditions (clouds). (b) Ratios of $f\left(\mathrm{x}, t_{\mathrm{O}_{3}}, T^{\circ}\right)$ (based on simulated actinic flux spectra) and $f_{\mathrm{SR}}$ (calculated from measured actinic flux spectra). (c) Ratios $j\left(\mathrm{O}^{1} \mathrm{D}\right)_{\mathrm{FR}} / j\left(\mathrm{O}^{1} \mathrm{D}\right)_{\mathrm{SR}}$ where $j\left(\mathrm{O}^{1} \mathrm{D}\right)_{\mathrm{FR}}$ was calculated according to equation 17. In both cases a constant ambient temperature of $295 \mathrm{~K}$ was assumed. 


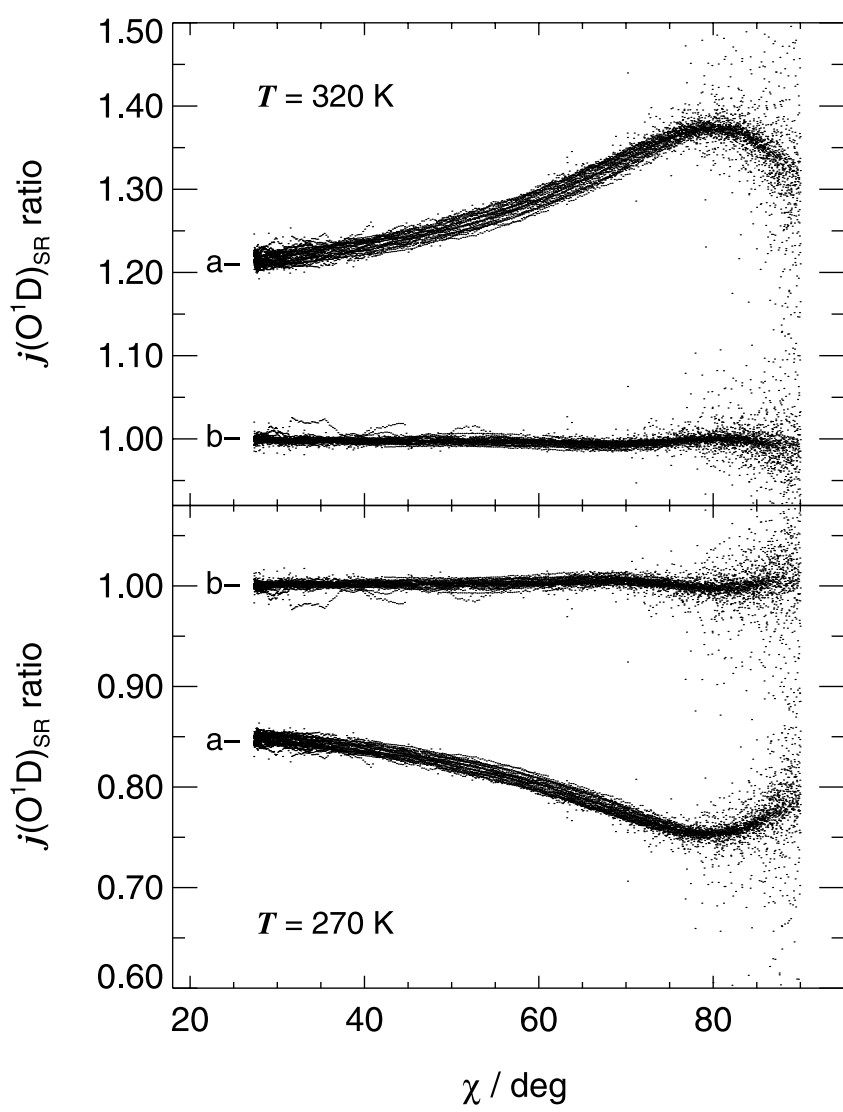

Figure 7. Zenith angle dependencies of ratios of photolysis frequencies calculated from JCOM97 spectroradiometer data assuming different, constant temperatures. For line a, $j\left(\mathrm{O}^{1} \mathrm{D}\right)_{\mathrm{SR}}(T) / j\left(\mathrm{O}^{1} \mathrm{D}\right)_{\mathrm{SR}}(295 \mathrm{~K})$ at $T=320$ and $270 \mathrm{~K}$ (top and bottom panel, respectively). For line $\mathrm{b}$, $j\left(\mathrm{O}^{1} \mathrm{D}\right)_{\mathrm{SR}}(T) /\left(j\left(\mathrm{O}^{1} \mathrm{D}\right)_{\mathrm{SR}}(295 \mathrm{~K}) b\left(\chi, t_{\mathrm{O}_{3}}, T\right)\right)$.

Thus $A_{0}$ is accessible from the quantities obtained in the laboratory $\left(D_{\text {abs }}, Z_{H}\left(\chi^{\circ}\right), D_{\text {rel }}\right)$ and the actinic flux spectrum simulated for the selected standard conditions. In the present example a factor $A_{0}=(7.6 \pm 0.6) \cdot 10^{-6} \mathrm{~s}^{-1} \mathrm{~V}^{-1}$ was derived. The error limit contains those of the parameters $D_{\text {abs }}$ and $Z_{\mathrm{H}}\left(\chi^{\circ}\right)$ as well as an estimated additional $2 \%$ error introduced by the uncertainties of the experimentally obtained $D_{\text {rel }}$ in the above integration.

\section{Results and Discussion}

\subsection{Comparison With a Spectroradiometer}

[27] In order to test the factors $A_{0}$ and $f\left(\chi, t_{\mathrm{O}_{3}}, T^{\circ}\right)$, experimental data obtained in the course of a field campaign at Jülich, Germany $\left(50.9^{\circ} \mathrm{N}, 6.4^{\circ} \mathrm{E}\right)$ from 10-27 June 1997 were analyzed. During this campaign (JCOM97) a spectroradiometer and the $j\left(\mathrm{O}^{1} \mathrm{D}\right)$-filterradiometer were operated simultaneously. However, the main aim of JCOM97 was an intercomparison of the spectroradiometer with a chemical actinometer measuring $j\left(\mathrm{NO}_{2}\right)$ [Kraus et al., 2000].

[28] For comparison with the $j\left(\mathrm{O}^{1} \mathrm{D}\right)$-filterradiometer the actinic flux spectra $F_{\lambda}$ recorded by the spectroradiometer were analyzed according to equation 4 to obtain $j\left(\mathrm{O}^{1} \mathrm{D}\right)_{\mathrm{SR}}$. In this calculation a constant ambient temperature of $295 \mathrm{~K}$ was assumed and the molecular data by Malicet et al. [1995] and
Talukdar et al. [1998] were used. More details concerning the spectroradiometer and the accuracy of the actinic flux spectra measurements are given elsewhere [Hofzumahaus et al., 1999]. In Figure 6a the $j\left(\mathrm{O}^{1} \mathrm{D}\right)_{\mathrm{SR}}$ are plotted against solar zenith angle. The dependence is strongly variable because during JCOM97 cloudy conditions prevailed.

[29] The factors $f\left(\mathrm{X}, t_{\mathrm{O}_{3}}, T^{\circ}\right)$ were calculated for the JCOM97 conditions using the parametrization derived in section 3.2. The input data needed for this calculation, namely solar zenith angle and ozone column, were obtained by calculation (dependent on time of day and geographical position) and from satellites (NASA-Earth Probe, Total Ozone Mapping Spectrometer (TOMS)), respectively. Moreover, the corresponding factors $f_{\mathrm{SR}}$ were calculated according to equation 18 from the spectra measured by the spectroradiometer. In Figure $6 \mathrm{~b}$ the ratios $f\left(\chi, t_{\mathrm{O}_{3}}, T^{\circ}\right) / f_{\mathrm{SR}}$ are shown as a function of solar zenith angle. Although $f(\chi$, $\left.t_{\mathrm{O}}, T^{\circ}\right)$ is based on simulated spectra for clear sky conditions the ratios are close to unity also under cloudy conditions. This can be explained by the small influence of clouds on the shape of the solar actinic flux spectrum in the narrow wavelength range monitored by the filterradiometer. Thus the simulated actinic flux spectra are suitable for the calculation of $f\left(\chi, t_{\mathrm{O}_{3}}, T^{\circ}\right)$, for the conditions during JCOM97 ( $\left.\chi \geq 28^{\circ}, t_{\mathrm{O}_{3}}=315-380 \mathrm{DU}\right)$. However, there remains a slight increase of the ratios toward higher solar zenith angles. The mean is 1.007 with a standard deviation of $1.5 \%$ at $\chi \leq 70^{\circ}$. In the range $\chi=70-85^{\circ}$ the ratio rises to an averaged value of 1.025 with a standard deviation of $5.1 \%$. The reason for this deviation could be the limited spectral resolution of the simulated spectra in the range above $315 \mathrm{~nm}$ or more general problems of accurately modeling the actinic flux at high solar zenith angles.

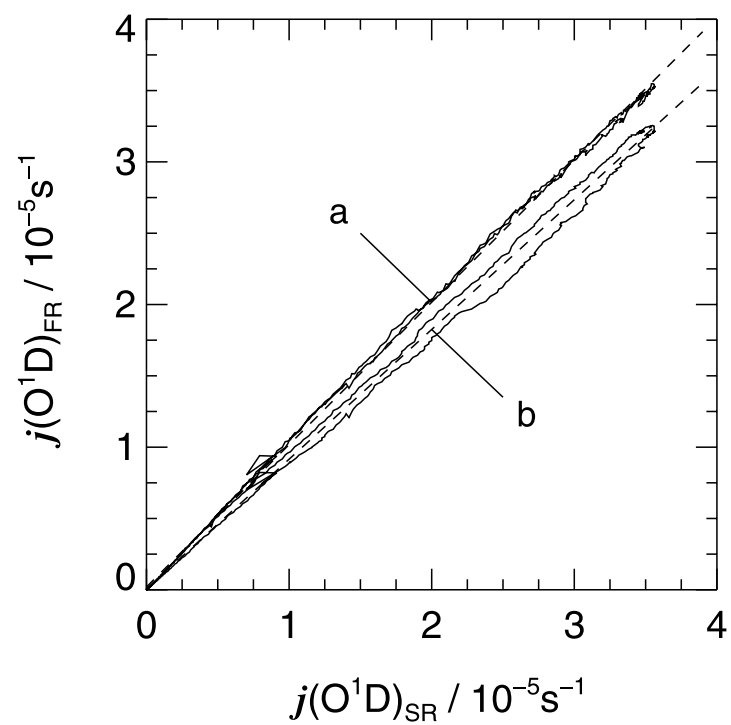

Figure 8. Correlation of $j\left(\mathrm{O}^{1} \mathrm{D}\right)_{\mathrm{SR}}$ and $j\left(\mathrm{O}^{1} \mathrm{D}\right)_{\mathrm{FR}}$ on 19 June 1998 during the IPMMI campaign. $j\left(\mathrm{O}^{1} \mathrm{D}\right)_{\mathrm{SR}}$ was calculated considering actual temperatures in a simultaneously measuring chemical actinometer. Temperatures were ranging from $287 \mathrm{~K}$ in the morning to $318 \mathrm{~K}$ in the afternoon. For line a, $j\left(\mathrm{O}^{1} \mathrm{D}\right)_{\mathrm{FR}}$ taking into account the same temperatures by applying the factor $b\left(\mathrm{\chi}, t_{\mathrm{O}}, T\right)$. For line $\mathrm{b}$, $j\left(\mathrm{O}^{1} \mathrm{D}\right)_{\mathrm{FR}}$ assuming constant temperature. Dashed lines show linear regressions to the data sets. 
Table 1. Relative Error Contributions to $j\left(\mathrm{O}^{1} \mathrm{D}\right)$ Measured With a Filterradiometer $^{\mathrm{a}}$

\begin{tabular}{lcc}
\hline Quantity & $\chi$-Range & Error $/ \%$ \\
\hline$A_{0}$ & $\chi \leq 85$ & 6 \\
$f\left(\chi, t_{\mathrm{O}_{3}}, T^{\circ}\right)$ & $\chi \leq 70$ & 3 \\
$b\left(\chi, t_{\mathrm{O}_{3}}, T\right)$ & $70 \leq x \leq 85$ & 7 \\
$j\left(\mathrm{O}^{1} \mathrm{D}\right)$ & $70 \leq \mathrm{x} \leq 85$ & 1 \\
& $70 \leq x \leq 85$ & 2 \\
& $x \leq 70$ & 10 \\
\hline
\end{tabular}

${ }^{\mathrm{a}}$ Uncertainties concerned with molecular data of ozone $(\sigma, \phi)$ are not considered (see text).

[30] In Figure $6 c$ the ratio $j\left(\mathrm{O}^{1} \mathrm{D}\right)_{\mathrm{FR}} / j\left(\mathrm{O}^{1} \mathrm{D}\right)_{\mathrm{SR}}$ is shown after the filterradiometer signals $U$ were converted to $j\left(\mathrm{O}^{1} \mathrm{D}\right)_{\mathrm{FR}}$ by applying $A_{0}$ and $f\left(\mathrm{\chi}, t_{\mathrm{O}_{3}}, T^{\circ}\right)$. Compared to Figure $3 \mathrm{f}$ there are two major improvements recognizable. Firstly, the zenith angle dependence has virtually vanished. Secondly, the ratio is close to unity. A linear regression of the data yields a slope of 0.960 and a negligible intercept of $-8 \cdot 10^{-9} \mathrm{~s}^{-1}$. The systematic $4 \%$ difference is within the estimated uncertainty of the absolute radiometric calibration of both instruments. This demonstrates the applicability of both the proportionality factor $A_{0}$ derived from the laboratory calibration as well as the correction function $f\left(\chi, t_{\mathrm{O}_{3}}\right.$, $\left.T^{\circ}\right)$. Note that the ratios in Figure 6c would reveal an incorrect $D_{\text {rel }}$ which is not the case in Figure $6 \mathrm{~b}$.

[31] The remaining scatter in Figure 6c is mainly caused by an imperfect synchronization of the measurement techniques. While the FR output was recorded by averaging over $60 \mathrm{~s}$ time-intervals, the spectroradiometer measures more momentary values approximately every $70 \mathrm{~s}$ during the scans. Under cloudy conditions with sometimes fast changing cloud cover this results in increased scatter. However, although these unfavorable conditions prevailed during JCOM97 the standard deviation of the ratio is no more than $3 \%$ for $\chi \leq 70^{\circ}$ and $8 \%$ in the range $\chi=70-85^{\circ}$.

\subsection{Temperature Dependence of $j\left(\mathrm{O}^{1} \mathrm{D}\right)$}

[32] The verification of the factor $b\left(\chi, t_{\mathrm{O}_{3}}, T\right)$ was not tested by considering actual ambient temperatures during JCOM97. A different approach was used for two reasons. Firstly, ambient temperature changes were relatively small for seasonal reasons $(\leq 10 \mathrm{~K})$, i.e., compared with Figure 6, negligible changes are expected. Secondly, as mentioned above, the $b\left(\chi, t_{\mathrm{O}_{3}}, T\right)$ are applicable to any instrument. Thus they were tested with the spectroradiometer data which removes any underlying scatter caused by imperfect synchronization of instruments.

[33] $j\left(\mathrm{O}^{1} \mathrm{D}\right)_{\mathrm{SR}}$ was calculated from the measured actinic flux spectra for hypothetical, constant temperatures of $270 \mathrm{~K}$ and $320 \mathrm{~K}$. In Figure 7 the ratios with the $j\left(\mathrm{O}^{1} \mathrm{D}\right)_{\mathrm{SR}}$ obtained for $295 \mathrm{~K}$ are plotted (Figure 7a). As expected from the results in section 3.3, these ratios show a dependence on solar zenith angle as well as a systematic deviation from unity. For comparison the same ratios were calculated after the $j\left(\mathrm{O}^{1} \mathrm{D}\right)$ at $295 \mathrm{~K}$ were multiplied by $b\left(\mathrm{\chi}, t_{\mathrm{O}_{3}}, T\right)$ with $T=$ $270 \mathrm{~K}$ and $320 \mathrm{~K}$, respectively (Figure $7 \mathrm{~b}$ ). As is evident from Figure 7 these ratios are very close unity, i.e., within $0.3 \%$ and a standard deviation of $0.4 \%$ for $x \leq 70^{\circ}$ and $2.0 \%$ in the range $\chi=70-85^{\circ}$. This shows the validity of the factor $b\left(\chi, t_{\mathrm{O}_{3}}, T\right)$ for the conditions at JCOM97 ( $\mathrm{\chi} \geq$ $\left.28^{\circ}, t_{\mathrm{O}_{3}}=315-380 \mathrm{DU}\right)$, i.e., the use of the temperature correction factors has virtually the same effect as considering the temperatures directly. This confirms the results in Figure $6 \mathrm{~b}$ where the applicability of the simulated solar actinic flux spectra has already been shown.

[34] In order to demonstrate the effects of neglecting the temperature dependence of $j\left(\mathrm{O}^{1} \mathrm{D}\right)$, results of the IPMMI campaign [Cantrell et al., 2003] are utilized as an example. During that campaign measurements of $j\left(\mathrm{O}^{1} \mathrm{D}\right)$ by a chemical actinometer, spectroradiometers and filterradiometers were compared under field conditions [Hofzumahaus et al., 2004]. For a meaningful comparison the radiometer data were derived for temperatures measured inside the chemical actinometer. In Figure 8 correlations between filterradiometer and spectroradiometer data are shown for a clear sky day (19 June 1998). On this day the actinometer temperature varied from $287 \mathrm{~K}$ in the morning to a maximum of $318 \mathrm{~K}$ in the afternoon. In Figure $8 j\left(\mathrm{O}^{1} \mathrm{D}\right)_{\mathrm{SR}}(T)$ is plotted against $j\left(\mathrm{O}^{1} \mathrm{D}\right)_{\mathrm{FR}}$ with the factor $b\left(\mathrm{X}, t_{\mathrm{O}_{3}}, T\right)$ being applied and neglected, respectively. The effect of neglecting the diurnal temperature change is twofold. Firstly, since temperature and $j\left(\mathrm{O}^{1} \mathrm{D}\right)$ are correlated also the slopes of linear regressions of the correlations $j\left(\mathrm{O}^{1} \mathrm{D}\right)_{\mathrm{SR}}$ versus $j\left(\mathrm{O}^{1} \mathrm{D}\right)_{\mathrm{FR}}$ differ by about $10 \%$. Secondly, there is a hysteresis because in the afternoon temperatures were higher than in the morning. It should be noted that the spectroradiometer rather than the actinometer was chosen as a reference in Figure 8 because the precisions of the radiometric measurements are comparable. Moreover, absolute agreement between the filterradiometer and the chemical actinometer also depends on the correctness of the molecular data used in the analysis $\left(\sigma\left(\mathrm{O}_{3}\right), \phi\left(\mathrm{O}^{1} \mathrm{D}\right)\right)$. This aspect is beyond the scope of this work and is addressed in the IPMMI campaign $j\left(\mathrm{O}^{1} \mathrm{D}\right)$ paper by Hofzumahaus et al. [2004] as well as in previous work [Müller et al., 1995]. Using the recent quantum yield data on $O\left({ }^{1} \mathrm{D}\right)$ formation by Talukdar et al. [1998] generally good agreement is obtained within the experimental uncertainties.

\section{Conclusion}

[35] Tropospheric $j\left(\mathrm{O}^{1} \mathrm{D}\right)$ values can be determined with high precision and time-resolution using filterradiometers. The accuracy of the conversion of the output signals to photolysis frequencies depends on (1) a thorough spectral and optical characterization of the device, (2) a theoretical consideration of the effects of the individual properties using simulated solar actinic flux spectra, and (3) the availability of additional data concerning the field site, namely total ozone column and solar zenith angle. Absolute calibration can be achieved by comparison with a reference method or by a laboratory calibration with an irradiance standard. Moreover, temperature must be considered in any field measurement, as well as in a calibration utilizing a chemical actinometer. Generally the accuracy of $j\left(\mathrm{O}^{1} \mathrm{D}\right)$ values determined with filterradiometers will depend on solar zenith angle due to the nonlinear character of the correction function. In the present example relative errors of $10 \%$ and $15 \%$ are finally estimated for solar zenith angle ranges $x \leq 70^{\circ}$ and $70 \leq x \leq 85^{\circ}$, respectively. Table 1 shows the contributions of different error sources.

[36] It should be noted that the calibration function derived in this work is valid at ground level and, except 
Table A1. Polynomial Coefficients ${ }^{\mathrm{a}}$

\begin{tabular}{|c|c|c|c|c|c|c|c|c|c|}
\hline$n$ & 0 & 1 & 2 & 3 & 4 & 5 & 6 & 7 & 8 \\
\hline$a_{01 n}$ & $1.083(-2)$ & $1.625(-2)$ & $-2.562(-2)$ & $-1.393(-1)$ & $3.922(-1)$ & $-3.660(-1)$ & $1.187(-1)$ & & \\
\hline$a_{02 n}$ & $4.341(-6)$ & $-4.971(-5)$ & $3.625(-4)$ & $9.878(-4)$ & $-9.647(-3)$ & $2.460(-2)$ & $-3.011(-2)$ & $1.832(-2)$ & $-4.455(-3)$ \\
\hline$a_{03 n}$ & $-1.981(-8)$ & $1.454(-7)$ & $-4.010(-6)$ & $2.342(-5)$ & $-6.202(-5)$ & $8.899(-5)$ & $-7.145(-5)$ & $3.004(-5)$ & $-5.099(-6)$ \\
\hline$a_{11 n}$ & $8.675(-5)$ & $2.178(-4)$ & $-7.147(-4)$ & $-9.652(-5)$ & $2.190(-3)$ & $-2.537(-3)$ & $9.021(-4)$ & & \\
\hline$a_{12 n}$ & $5.079(-8)$ & $-7.948(-7)$ & $9.386(-6)$ & $-2.485(-5)$ & $5.069(-6)$ & $7.942(-5)$ & $-1.438(-4)$ & $1.032(-4)$ & $-2.752(-5)$ \\
\hline$a_{13 n}$ & $-5.451(-11)$ & $-2.727(-9)$ & $-7.712(-9)$ & $1.233(-7)$ & $-4.085(-7)$ & $6.376(-7)$ & $-5.170(-7)$ & $2.039(-7)$ & $-2.890(-8)$ \\
\hline
\end{tabular}

${ }^{\mathrm{a}}$ Numbers in brackets are exponents to base 10 .

from the relative temperature dependence, only for the particular instrument described here. Other instruments must be characterized accordingly prior to use and special field conditions (e.g., high altitudes or extreme pollution), should be considered in the simulated solar actinic flux spectra to derive the correction function. However, due to the low impact of cloud cover as demonstrated in this paper we expect the correction function to be insensitive toward changes in albedo (e.g., snow cover) and altitude in a moderate range. Nevertheless, regular radiometric calibrations or intercomparisons with other reference methods are recommended to check the long-term stability of a filterradiometer especially under continuous field measurement conditions.

\section{Appendix A: Parametrization of the Temperature Correction Factor}

\section{A1. Equations}

$$
\begin{aligned}
b\left(\mathrm{\chi}, t_{\mathrm{O}_{3}}, T\right)= & 1+a_{0}(T / \mathrm{K}-295)+a_{1}(T / \mathrm{K}-295)^{2} \\
a_{0}= & a_{01}+a_{02}\left(t_{\mathrm{O}_{3}} / \mathrm{DU}-350\right)+a_{03}\left(t_{\mathrm{O}_{3}} / \mathrm{DU}\right. \\
& -350)^{2} \\
a_{1}= & a_{11}+a_{12}\left(t_{\mathrm{O}_{3}} / \mathrm{DU}-350\right)+a_{13}\left(t_{\mathrm{O}_{3}} / \mathrm{DU}\right. \\
& -350)^{2} \\
a_{01}= & a_{010}+a_{011} \cos (\mathrm{\chi})+a_{012} \cos (\mathrm{\chi})^{2} \\
& +\cdots+a_{01 n} \cos (\mathrm{\chi})^{n} \\
a_{02}= & \cdots \\
a_{03}= & a_{030}+a_{031} \cos (\mathrm{\chi})+a_{032} \cos (\mathrm{\chi})^{2}+\cdots \\
& +a_{03 n} \cos (\mathrm{\chi})^{n} \\
a_{11}= & a_{110}+a_{111} \cos (\mathrm{\chi})+a_{112} \cos (\mathrm{\chi})^{2}+\cdots \\
& +a_{11 n} \cos (\mathrm{\chi})^{n} \\
a_{12}= & \cdots \\
a_{13}= & a_{130}+a_{131} \cos (\mathrm{\chi})+a_{132} \cos (\mathrm{\chi})^{2}+\cdots \\
& +a_{13 n} \cos (\mathrm{\chi})^{n}
\end{aligned}
$$

The polynomial coefficients are given in Table A1.

[37] Acknowledgments. This work was supported by Meteorologie Consult GmbH (M.M.), the Bundesminister für Wissenschaft, Bildung, Forschung und Technologie, grant 422-4007-07 TFS 30/B.2 (A.K.) and the Helmholtz-Gemeinschaft (B.B.). The authors thank E.-P. Röth for providing simulated solar actinic flux spectra.

\section{References}

Bahe, F. C., W. N. Marx, U. Schurath, and E. P. Röth (1979), Determination of the absolute photolysis rate of ozone by sunlight, $\mathrm{O}_{3}+h \nu \rightarrow \mathrm{O}\left({ }^{1} \mathrm{D}\right)+$ $\mathrm{O}_{2}\left({ }^{1} \Delta_{g}\right)$, at ground level, Atmos. Environ., 13, 1515-1522.
Bahe, F. C., U. Schurath, and K. H. Becker (1980), The frequency of $\mathrm{NO}_{2}$ photolysis at ground level as recorded by a continuous actinometer, Atmos. Environ., 14, 711-718.

Bais, A. F., et al. (2003), International photolysis frequency measurement and model intercomparison (IPMMI): Spectral actinic solar flux measurements and modeling, J. Geophys. Res., 108(D16), 8543, doi:10.1029/ 2002JD002891.

Brauers, T., H. Koch, H.-P. Dorn, and C. Plass-Dülmer (1998), Meteorological aspects, ozone, and solar radiation measurements during POPCORN 1994, J. Atmos. Chem., 31, 99-100.

Cantrell, C. A., J. G. Calvert, A. F. Bais, R. E. Shetter, B. L. Lefer, and G. D. Edwards (2003), Overview and conclusions of the international photolysis frequency measurement and modeling intercomparison (IPMMI) study, J. Geophys. Res., 108(D16), 8542, doi:10.1029/ 2002JD002962.

Dickerson, R. R., D. H. Stedman, and A. C. Delany (1982), Direct measurements of ozone and nitrogen dioxide photolysis rates in the troposphere, J. Geophys. Res., 87, 4933-4946.

Eckstein, E., D. Perner, C. Brühl, and T. Trautmann (2002), A new actinic flux $4 \pi$-spectroradiometer: Experiment and cloud effects, Atmos. Chem. Phys. Discuss., 2, 1939-1977.

Edwards, G. D., and P. S. Monks (2003), Performance of a single monochromator diode array spectroradiometer for the determination of actinic flux and atmospheric photolysis frequencies, J. Geophys. Res., 108(D16), 8546, doi:10.1029/2002JD002844.

Hofzumahaus, A., T. Brauers, U. Platt, and J. Callies (1992), Latitudinal variation of measured $\mathrm{O}_{3}$ photolysis frequencies $\mathrm{J}\left(\mathrm{O}^{1} \mathrm{D}\right)$ and primary $\mathrm{OH}$ production rates over the atlantic ocean between $50^{\circ} \mathrm{N}$ and $30^{\circ} \mathrm{S}$, J. Atmos. Chem., 15, 283-298.

Hofzumahaus, A., A. Kraus, and M. Müller (1999), Solar actinic flux spectroradiometry: A technique for measuring photolysis frequencies in the atmosphere, Appl. Opt., 38, 4443-4460.

Hofzumahaus, A., et al. (2004), Photolysis frequency of $\mathrm{O}_{3}$ to $\mathrm{O}\left({ }^{1} \mathrm{D}\right)$ : Measurement and modelling during the International Photolysis Frequency Measurement and Modelling Intercomparision (IPMMI), J. Geophys. Res., 109, D08S90, doi:10.1029/2003JD004333.

Junkermann, W., U. Platt, and A. Volz-Thomas (1989), A photoelectric detector for the measurement of photolysis frequencies of ozone and other atmospheric molecules, J. Atmos. Chem., 8, 203-227.

Kraus, A., and A. Hofzumahaus (1998), Field measurements of atmospheric photolysis frequencies for $\mathrm{O}_{3}, \mathrm{NO}_{2}, \mathrm{HCHO}, \mathrm{H}_{2} \mathrm{O}_{2}$ and $\mathrm{HONO}$ by UV spectroradiometry, J. Atmos. Chem., 31(1-2), 161-180.

Kraus, A., F. Rohrer, and A. Hofzumahaus (2000), Intercomparison of $\mathrm{NO}_{2}$ photolysis frequency measurements by actinic flux spectroradiometry and chemical actinometry during JCOM97, Geophys. Res. Lett., 27, $1115-1118$.

Kylling, A., et al. (2003), Actinic flux determination from measurements of irradiance, J. Geophys. Res., 108(D16), 4506, doi:10.1029/ 2002JD003236.

Lantz, K. O., P. Disterhoft, J. J. DeLuisi, E. Early, A. Thompson, D. Bigelow, and J. Slusser (1998), Methodology for deriving clear-sky erythemal calibration factors for UV broadband radiometers of the U.S. central UV calibration facility, J. Atmos. Oceanic Technol., 16, 17361752 .

Madronich, S. (1987), Photodissociation in the atmosphere: 1. Actinic flux and the effects of ground reflection and clouds, J. Geophys. Res., 92, $9740-9752$.

Malicet, J., D. Daumont, J. Charbonnier, C. Parisse, A. Chakir, and J. Brion (1995), Ozone UV spectroscopy II: Absorption cross-sections and temperature dependence, J. Atmos. Chem., 21, 263-273.

McKenzie, R., P. Johnston, A. Hofzumahaus, A. Kraus, S. Madronich, C. A. Cantrell, J. G. Calvert, and R. E. Shetter (2002), Relationship between photolysis frequencies derived from spectroscopic measurements of actinic fluxes and irradiances during the IPMMI campaign, J. Geophys. Res., 107(D5), 4042, doi:10.1029/2001JD000601.

Müller, M. (1994), Messung der aktinischen ultravioletten Strahlung und der Ozon-Photolysefrequenz in der Atmosphäre mittels Filterradiometrie und Spektralradiometrie, Ph.D. thesis, Univ. of Bonn, Bonn, Germany. 
Müller, M., A. Kraus, and A. Hofzumahaus (1995), $\mathrm{O}^{3} \rightarrow \mathrm{O}\left({ }^{1} \mathrm{D}\right)$ photolysis frequencies determined from spectroradiometric measurements of solar actinic UV-radiation: Comparison with chemical actinometer measurements, Geophys. Res. Lett., 22, 679-682.

Shetter, R. E., and M. Müller (1999), Photolysis frequency measurements using actinic flux spectroradiometry during PEM-Tropics mission: Instrumentation description and some results, J. Geophys. Res., 104, 56475661.

Shetter, R. E., et al. (1996), Actinometric and radiometric measurement and modeling of the photolysis rate coefficient of ozone to $\mathrm{O}\left({ }^{1} \mathrm{D}\right)$ during the Mauna Loa Observatory Photochemistry Experiment 2, J. Geophys. Res., $101,10,631-10,642$.

Shetter, R. E., et al. (2003), Photolysis frequency of $\mathrm{NO}_{2}$ : Measurement and modelling during the international photolysis frequency measurement and modelling intercomparision (IPMMI), J. Geophys. Res., 108(D16), 8544, doi:10.1029/2002JD002932.

Talukdar, R. K., C. A. Longfellow, M. K. Gilles, and A. R. Ravishankara (1998), Quantum yields of $\mathrm{O}\left({ }^{1} \mathrm{D}\right)$ in the photolysis of ozone between 289 and $329 \mathrm{~nm}$ as a function of temperature, Geophys. Res. Lett., 25(2), $143-146$.

Volz-Thomas, A., A. Lerner, H.-W. Pätz, M. Schultz, D. S. McKenna, R. Schmitt, S. Madronich, and E. P. Röth (1996), Airborne measurements of the photolysis frequency of $\mathrm{NO}_{2}$, J. Geophys. Res., 101(D13), $18,613-18,627$

Webb, A. R, et al. (2002), Measuring spectral actinic flux and irradiance: Experimental results from the admira (actinic flux determination from measurements of irradiance) projekt, J. Atmos. Oceanic Technol., 19, $1049-1062$.

B. Bohn, A. Hofzumahaus, A. Kraus, and M. Müller, Institut für Chemie und Dynamik der Geosphäre II: Troposphäre, Forschungszentrum Jülich, D-52425 Jülich, Germany. (b.bohn@fz-juelich.de) 